\title{
A condição das mulheres em Mary Wollstonecraft e Simone de Beauvoir
}

\section{Women's condition in Mary Wollstonecraft and Simone de Beauvoir}

Dra. Ana Carla de Abreu Siqueira carladeabreus@gmail.com Universidade Federal do Ceará

O objetivo deste artigo é apresentar alguns elementos fundamentais nos pensamentos de Mary Wollstonecraft e Simone de Beauvoir. Em um primeiro momento, apresentamos as ideias de Wollstonecraft sobre a educação. O sistema de instrução não seguia os princípios iluministas que deveriam mostrar homens e mulheres como seres igualmente racionais e, portanto, detentores dos mesmos direitos. Em seguida, mostramos algumas considerações de Beauvoir acerca do sexismo biológico. A pensadora existencialista defendia que a situação é mais determinante da existência do que qualquer suposta essência feminina. Neste sentido, falamos sobre algumas propostas que nos podem ajudar a construir um pensar filosófico em torno da condição das mulheres.

PALAVRAS-CHAVE

Feminismo. Filosofia. Mary Wollstonecraft.

Simone de Beauvoir.

This paper aims to present some fundamental elements in Mary Wollstonecraft and Simone de Beauvoir's thoughts. At first, we present Wollstonecraft's ideas about education. The educational system does not follow the enlightened criteria that shows men and women as equally rational beings and therefore holders of the same rights. Then, we show some of Beauvoir's considerations about biological sexism. The existentialist thinker posited that the situation is more determinant of our existence than any supposed feminine essence. In this sense, we talk about some proposals that can help create philosophical thinking around women's conditions. 
Embora temporalmente distantes, a filósofa inglesa Mary Wollstonecraft (1759-1797) e a filósofa francesa Simone de Beauvoir (1908-1986) são pensadoras que se destacam na história da filosofia pela originalidade de seus conceitos e dialogam entre si sobre a condição das mulheres. A partir de suas experiências particulares e de interpretações dos autores que ocupavam o cânone, cada uma delas soube olhar para a própria existência e avaliar criticamente a situação vivida. Com isso, elas também articularam as ideias de seu tempo e ensinaram novas abordagens da história. Para compreendermos a filosofia como crítica da condição das mulheres, analisamos algumas premissas fundamentais das duas autoras e exploramos algumas de suas contribuições ao debate. Como resultado, podemos indicar formas de uso da filosofia para o aprofundamento de uma reflexão em relação às questões de gênero.

O livro Reivindicação dos direitos da mulher (1792), de autoria da iluminista Mary Wollstonecraft, foi escrito em parte como resposta às observações de Jean-Jacques Rousseau sobre a educação das meninas, mas especialmente como uma contraposição aos ideais do antigo bispo de Autun, que publicou um documento atestando que a educação feminina deveria estar submetida à família, ao passo que os homens teriam direito a uma instrução pública. Assim, a autora dedicou sua obra ao senhor Talleyrand-Périgord e declarou: "eu advogo por meu sexo, não por mim mesma” (WOLLSTONECRAFT, 2016, p. 17). No mesmo caminho questionador e exploratório, a obra da existencialista Simone de Beauvoir intitulada $O$ segundo sexo (1949) se tornou um marco para o pensamento feminista. Mas é importante destacar que essa extensa obra é um tratado fundamentalmente filosófico.

Como interpreta Fernanda Henriques (2016, p. 144), Beauvoir destaca em seu texto uma "fenomenologia da situação das mulheres e da chamada condição feminina em situações históricas determinadas, bem como no espaço simbólico das representações culturais”. Segundo Beauvoir, Wollstonecraft participou dos esboços do feminismo na Inglaterra, mas como em muitos lugares àquela época, o movimento ainda carecia de bases mais sólidas. E os fatores sociais do próprio tempo da existencialista contribuíram para que tais reivindicações ganhassem mais alcance e substância (BEAUVOIR, 2016a, p. 175). Este texto apresenta pensadoras que nos trouxeram obras revolucionárias e que até hoje são discutidas - ainda que precisem de atualizações em certos aspectos. Assim, a escolha das autoras também se deve ao fato de que as duas reconheceram as construções sociais que definem a mulher e seu comportamento, em vez de se deterem à suposição de que há uma essência feminina. 


\section{Mary Wollstonecraft e a crítica iluminista à educação}

Mary Wollstonecraft é uma autora fundamental para entendermos a exclusão feminina da vida pública. Em Reivindicação dos direitos da mulher ela examina a sociedade e o processo que levou toda mulher a seguir um papel específico, o qual deveria estar de acordo com uma suposta natureza frágil, sensível e menos racional. Apesar do título, a intenção da obra é muito mais falar que o destino da mulher é resultado de opressões do que servir como manifesto estritamente político e social dos seus direitos (MIRANDA, 2010, p. 141-142). Para os ideais iluministas de liberdade de pensamento e universalidade do sujeito, a razão deveria ser igualmente emancipadora em todos os seres humanos. No entanto, por não equiparar homens e mulheres, esse movimento filosófico teria sido contraditório em si mesmo. A historiadora Anadir dos Reis Miranda relata que:

Apesar de concebê-las como parte da espécie humana, o discurso iluminista afirmava que elas eram inferiores, tanto física, quanto intelectualmente, cabendo viverem sob o julgo da autoridade masculina, ideia incompatível com um dos mais importantes ideários iluministas, o referente ao uso autônomo da razão (MIRANDA, 2010, p. 112).

Foi também com a separação entre consciência e mundo, ocorrida com o advento do cogito cartesiano a partir da modernidade, que a filosofia não discutiu devidamente os problemas em relação ao gênero e ao que significa ser mulher. Patricia Ketzer (2017, p. 98) ressalta que "os conceitos epistemológicos foram construídos a partir de estereótipos de masculinidade, como o conceito de razão e de objetividade". Uma vez que Descartes atribuiu à razão a fonte de todo saber e, com isso, o corpo foi rebaixado no processo de conhecimento, não haveria necessidade de (1) situar o saber humano numa esfera social que levaria em consideração os eventos da vida em comum e, em especial, de (2) haver questões relativas às especificidades de gênero, já que a racionalidade seria isenta de diferenças e, portanto, constituir-se-ia como algo universal. O problema nessa perspectiva foi ela ter sido criada por aqueles que detinham o privilégio de estudar, ou seja, tal modelo compreendia em si apenas os homens brancos que excluíram tudo aquilo que consideraram o outro (KETZER, 2017, p. 97).

Sem autonomia, as mulheres ficaram impedidas do domínio absoluto sobre a própria razão. Wollstonecraft percebeu cedo e a partir de suas próprias experiências que as relações de gênero eram determinantes, pois sua educação não foi voltada a qualquer profissão e ela carecia dos privilégios que cabiam ao seu úni- 
co irmão homem. O caminho que lhe restava era justamente o casamento, mas devido à falta de dinheiro e herança, além de suas críticas pessoais ao matrimônio, ela se viu diante da necessidade de adquirir independência. Assim, passou por várias ocupações consideradas femininas (governanta de família aristocrática e dama de companhia, por exemplo) até entrar em contato com os reformistas que defendiam o uso livre da razão - especialmente pela educação (MIRANDA, 2010, p. 115-120). Foi durante o período de emprego estável em uma casa editorial que ela desenvolveu a escrita e, sobre isso, Miranda observa que:

Trabalhando a pleno rendimento, Wollstonecraft chegou a publicar, ao longo de três anos, quase trezentas resenhas que incluíam novelas, obras de teatro, ensaios sobre educação, tratados políticos e religiosos, entre outros. Essa atividade intensa lhe proporcionou a independência pessoal que sempre buscara e a possibilidade de ampliar e completar sua educação (MIRANDA, 2010, p. 121).

A filósofa se deparou com um sistema de educação criado por homens - e para os homens - que tinha o objetivo de transformar as mulheres em pessoas românticas, passivas e ingênuas. No caso, elas jamais seriam criadas para desenvolver suas habilidades, escrever, filosofar, governar ou comandar, pois "a força e a utilidade são sacrificadas à beleza" (WOLLSTONECRAFT, 2016, p. 25). Todavia, Wollstonecraft questiona: se as virtudes são alcançadas pelo uso da razão, por que somente homens puderam desenvolver as suas? Porque a educação feminina tinha como objetivo negar sua racionalidade a fim de criar mulheres submissas, superficiais e interessadas apenas nos acontecimentos próprios ao espaço privado, justamente com a desculpa de que sua natureza seria mais fraca e de que seus interesses estariam limitados.

Seguindo o exemplo da educação proposta pelo filósofo suíço Jean-Jacques Rousseau ${ }^{1}$, no que diz respeito à relação individual do sujeito com a sociedade, a mulher seria destinada a obedecer e agradar aos homens a partir da crença de que sua meta de vida seria conquistar um marido que lhe proporcionasse uma

1 Rousseau sugeriu que a sociedade corrompia a natureza humana e, por isso, a educação seria um passo necessário para libertá-lo da maldade e resgatar sua bondade natural. Porém, seu modelo de educação contemplaria somente os homens, enquanto as mulheres estariam destinadas a obedecê-los e agradá-los, reforçando sua dependência por uma suposta inferioridade. Segundo Fernanda Henriques: "A obra pedagógica de Rousseau é, sem sombra de dúvida, o legado mais funesto que as mulheres herdaram e, lamentavelmente, herdaram-no de alguém que representa, na memória histórica, uma referência fundamental para pensar a democracia e a educação" (HENRIQUES, 2016, p. 91). 
vida digna e, posteriormente, confinar seus interesses na esfera privada do lar. Um dos pontos onde podemos observar a indicação de que toda instrução era construída sobre a ideia de natureza feminina está na afirmação da pensadora de que o homem foi definido como superior à mulher por conta de sua força física. Assim ela prossegue a discussão:

Mas continuo insistindo que não só a virtude, como também o conhecimento dos dois sexos deveria ser o mesmo em natureza, se não em grau, e que as mulheres, consideradas criaturas não apenas morais, como também racionais, deveriam se esforçar para adquirir virtudes humanas (ou perfeições) mediante os mesmos meios que os homens, em vez de serem educadas como uma espécie de criatura imaginária pela metade - uma das extravagantes quimeras de Rousseau (WOLLSTONECRAFT, 2016, p. 62).

Portanto, desde a primeira educação, as mulheres são ensinadas a buscar um ideal de feminilidade, excelência e beleza, o que acaba por conduzi-las em direção à inatividade. A mulher é considerada submissa porque seu entendimento fora negligenciado por um modelo de instrução que procurava lhe atribuir obediência, refinamento e decoro acima da capacidade de ter opiniões próprias e pensar por si mesma (WOLLSTONECRAFT, 2016, p. 87). A educação sempre serviu para formar aspectos morais da sociedade, mas teve um papel determinante para a transformação da mulher em sexo sentimental e inferior, na medida em que ela foi, por muitos séculos, estimulada a dedicar seu tempo à família, à aparência, aos cuidados com o lar e, em especial, à romantização excessiva dos próprios sentimentos ${ }^{2}$. Por seu turno, a filósofa reivindica igualdade para as mulheres, ao invés de ocupar um lugar de supremacia diante do sexo masculino e afirma que: "Não desejo que tenham poder sobre os homens, mas sobre si mesmas" (WOLLSTONECRAFT, 2016, p. 89).

Além disso, segundo Wollstonecraft, toda educação proposta em defesa da racionalidade feminina seria útil, pois além de adquirir poder sobre si, a boa instrução fortaleceria os gostos e a mulher educada se tornaria uma melhor companheira para o marido, assim como seria uma mãe preparada para a criação mais

2 A dedicação à vida amorosa prendia as mulheres a uma vida alienada e sem questionamentos, uma vez que, "por não serem levadas a exercitar seu entendimento, a maior parte das mulheres se transformava em seres sentimentais, controladas por suas paixões e sensações. Além disso, através de romances, músicas e poesias também eram levadas a cultivar noções românticas do amor, ou seja, a achar que o objetivo principal de suas existências consistia em despertar a paixão ‘daquele que seria seu marido"” (MIRANDA, 2010, p. 136). 
correta de seus filhos e filhas. Essa tese certamente deve ser contestada, já que não é mais aceitável que o objetivo da educação signifique transformar mulheres em esposas e mães competentes. No entanto, é inegável o avanço trazido pela compreensão das ideias da pensadora do século XVIII. Através de uma educação igualitária, as mulheres seriam mais úteis para a vida em sociedade e mais dignas de tomar decisões para a construção de uma vida justa, pois saber discernir entre o certo e o errado é a base para lutarmos contra toda injustiça e convertermos a verdade na mais profunda indagação, tomando como meta fundamental a própria liberdade.

É preciso ressaltar que essa instrução excluía as mulheres pobres, as quais estavam submetidas ao trabalho e, por isso, não precisariam receber uma educação adequada ao cultivo da razão. Por outro lado, a autora manifesta que a mulher pobre é sempre mais virtuosa, justamente porque ela não tem tempo para atividades triviais e para o cultivo exclusivo de uma boa aparência a fim de agradar ao sexo masculino. Essa posição era uma crítica evidente aos valores da sociedade aristocrática. Em todo caso, ela acreditava que as mulheres foram ensinadas a seguir uma vida calma e sem ocupações na sociedade. Mas diante da dominação masculina, uma das observações mais importantes - e que reflete bem a necessidade de combatermos a opressão - é a ideia de que as mulheres devem se sentir representadas no governo e isso só é possível quando elas podem escolher seus representantes e ocupar esses cargos. Wollstonecraft defende que:

As mulheres poderiam estudar a arte da cura e ser médicas e enfermeiras. [...] Elas também poderiam estudar política e fundamentar sua benevolência sobre uma base mais ampla, pois a leitura da história dificilmente será de maior utilidade do que as aventuras românticas, caso lida como mera biografia, sem que sejam observadas as personagens da época, o progresso político, as artes etc. [...] elas poderiam se dedicar a tarefas de várias espécies, caso fossem educadas de maneira mais ordenada (WOLLSTONECRAFT, 2016, p. 191).

Portanto, a educação igualitária é o caminho apontado para que as virtudes das mulheres sejam cultivadas. Como resultado de todas essas reflexões, a filósofa iluminista abriu caminho para outras teóricas do feminismo e usou a escrita para superar a subjugação e o silenciamento impostos às mulheres. Ela questionou o modelo de educação que provocava a ideia de que mulheres são seres menos racionais devido a uma suposta natureza feminina e que negava 
seus direitos ao espaço público. Ainda que o texto da filósofa não possa ser seguido à risca, devemos atentar para suas contribuições na construção de uma filosofia feminista, pois ela mostrou que colocar homens e mulheres no mesmo nível de racionalidade significa fazer a civilização avançar. Para Kate Lindemann (1991, p. 158), seu pensamento gravita em torno de quatro pontos principais: a natureza humana, ética, filosofia social e política, filosofia da educação.

A natureza humana prevalece como tema estrutural para a filósofa e o conceito é aplicado para lidar com suas ideias sobre sexo e gênero. A subjugação feminina não era um estado natural, porém, a parte inferior de uma hierarquia inventada pelos homens para que eles próprios se mantivessem em condição privilegiada e dominassem o exercício da razão, a qual, em realidade, é inerente a homens e mulheres na mesma proporção. Com o suporte do iluminismo, Wollstonecraft defende que a racionalidade jamais é determinada pelo sexo e que há uma natureza em comum sob a camada de tantas diferenças. Assim, ela afirma que:

\footnotetext{
A razão é, consequentemente, o simples poder do aperfeiçoamento ou, para falar com mais propriedade, o poder de discernir a verdade. Nesse sentido, cada indivíduo constitui um mundo em si mesmo. Evidencia-se mais em uns do que em outros, mas a natureza da razão deve ser a mesma em todos, se o vínculo que une a criatura e o Criador é uma emanação da Divindade. [...] com o homem sempre colocado entre ela e a razão, é sempre representada como se tivesse sido criada apenas para enxergar de modo nebuloso e aceitar as coisas em confiança. Mas, se dispensarmos essas teorias ilusórias e considerarmos a mulher como um todo, de maneira como deve ser, e não como parte do homem, a pergunta seria se ela possui razão ou não. Em caso afirmativo, o que por ora admitirei, ela não foi meramente criada para ser o consolo do homem, e o caráter sexual não deveria destruir o caráter humano (WOLLSTONECRAFT, 2016, p. 78).
}

Nesse sentido, as mulheres podem alcançar virtudes essenciais a qualquer ser humano, resumidas em "agir razoavelmente, usar a própria liberdade e respeitar a liberdade dos outros, fazer trabalho produtivo e ser pai/mãe com sabedoria" (LINDEMANN, 1991, p. 159). E em tal contexto, a pensadora inglesa também inscreve suas críticas às classes privilegiadas, fortalecendo sua filosofia social e política. Como é possível constatar no decorrer do seu texto, 
a filosofia da educação ${ }^{3}$ ganhou contorno e conteúdo imprescindíveis para uma reivindicação dos direitos da mulher; seu desejo era uma educação igualitária que permitisse o cultivo da mente (WOLLSTONECRAFT, 2016, p. 211). Do mesmo modo, em Reivindicação dos direitos da mulher, a autora defende o pressuposto de que meninos e meninas possam cultivar as mesmas virtudes, cumprir seus destinos e aprimorar a vida humana sobre a terra a partir de uma educação igualitária.

De fato, as mulheres deveriam ser beneficiadas pelo sistema de educação e adquirir autonomia. Para ser coerente com a primazia da racionalidade humana, o ideal moderno de desenvolvimento precisaria trazer em si uma igualdade entre homens e mulheres. Se Wollstonecraft foi uma prova de que existiam mulheres que não aceitaram passivamente esse sistema, Beauvoir fez justiça às suas lutas e aspirações levando uma vida dedicada aos estudos, ao saber filosófico e à elevação do pensamento. Como ela narra em suas memórias, "os livros alargavam-me o horizonte. [...] Não sabia muito bem se desejava escrever livros mais tarde, ou vendê-los, mas, a meus olhos, o mundo não comportava nada mais precioso" (BEAUVOIR, 2015, p. 50-51). E seus livros foram marcados pela preocupação com a existência concreta, incluindo um interesse primordial em questões feministas.

\section{Simone de Beauvoir e a crítica existencialista e fenomenológica ao sexismo biológico}

Simone de Beauvoir inicia o primeiro volume de $O$ segundo sexo expondo a condição das mulheres e observa que o assunto era bastante incômodo mesmo no século XX. Esse tratado fenomenológico, existencialista e feminista promoveu uma revisão dos aspectos biológicos, materialistas, históricos e psicanalíticos que definiram as mulheres. Pela imposição masculina, homens e mulheres foram colocados como dois polos opostos: respectivamente certo e errado, positivo e negativo, sujeito e outro. Enquanto o homem é visto como sujeito de forma evidente, a mulher precisa a todo instante provar que é mulher,

3 Lindemann destaca que o projeto filosófico de Mary Wollstonecraft sobre a educação foi construído a partir de seu conhecimento da tradição, mas as próprias vivências da autora resultaram em observações essenciais para uma libertação do sexo feminino e assim comenta: "Como grande parte da teoria educacional ocidental, as propostas de reforma de Wollstonecraft se baseiam em uma evidente psicologia filosófica, ética e filosofia social. Além disso, elas se beneficiam da experiência de Wollstonecraft como fundadora e professora de uma escola infantil e de seu conhecimento em primeira mão das tarefas e preocupações diárias das variadas classes da Inglaterra do século XVIII” (LINDEMANN, 1991, p.161). 
preenchendo requisitos específicos em relação ao seu corpo, às suas ideias e ao seu comportamento. Assim, as mulheres foram representadas como naturalmente frágeis, culpadas, servis, pecadoras e incompletas.

A noção de que a mulher é o outro do homem teve a biologia como um dos pressupostos. Uma vez que ela carrega os filhos em seu ventre e amamenta, seu papel muitas vezes se limitou a gerar vidas e permanecer na esfera privada, enquanto o homem podia se dedicar a uma vida individual e, ao mesmo tempo, desenvolver competências no mundo público. Para Beauvoir:

No homem não há nenhum hiato entre a vida pública e a privada: quanto mais ele afirma seu domínio do mundo pela ação e pelo trabalho, mais se revela viril; nele, os valores humanos e os valores vitais se confundem; ao passo que os êxitos autônomos da mulher estão em contradição com sua feminilidade, porquanto se exige da "verdadeira mulher" que se torne objeto, que seja o Outro (BEAUVOIR, 2016, p. 308).

O corpo se tornou um campo de disputa nessas relações de poder, pois não se trata de algo neutro e irrelevante. Embora homens e mulheres sejam dotados de corpos, apenas o homem é seu corpo de forma positiva, na medida em que tem domínio sobre suas funções corporais e liberdade em suas escolhas. Por sua vez, a mulher é corpo de forma empobrecida e está submetida ao solitário processo de preservação da espécie. Temos um corpo, o qual está no mundo e predisposto às suas contingências, porém, a biologia é insuficiente para nos determinar neste âmbito de experiências e sentido que é o mundo. Nas palavras da filósofa, o corpo é "instrumento de nosso domínio do mundo" (BEAUVOIR, 2016a, p. 60) em vez de uma prisão. E adiante ela afirma que "se o corpo não é uma coisa, é uma situação: é a nossa tomada de posse do mundo e o esboço de nossos projetos" (BEAUVOIR, 2016a, p. 62).

Apenas quando avaliamos a situação de existência e suas características mais específicas, como o corpo deve ser visto e respeitado, é que podemos compreender a situação da mulher em uma sociedade marcada por regras que reduzem corpos femininos a meros objetos quando determina padrões de beleza e comportamento. Frequentemente subjugada ao homem, definida como mais fraca e incapaz de realizar as mesmas tarefas, a mulher foi limitada pelo próprio corpo. No entanto, ao invés de ser um dado biológico em si, tal inferioridade é uma invenção social que surgiu com o propósito de colocá-la em um 
papel secundário em todos os campos da vida. $\mathrm{O}$ corpo está submetido às leis criadas pela sociedade; portanto, está submetido às leis criadas pelos homens.

Não é a biologia que transforma a mulher em mulher, senão aquilo que a sociedade faz dela e como determina seu papel de outro diante do predominante sexo masculino. Daí a famosa e acertada sentença que abre o segundo volume da obra $O$ segundo sexo: "Ninguém nasce mulher: torna-se mulher" (BEAUVOIR, 2016b, p. 11). Beauvoir enriquece sua discussão a partir de noções específicas, tais como facticidade, existência e corpo. O conceito de facticidade traz o pressuposto de que existe inevitavelmente uma situação de vida e indica que todos nós estamos cercados por um conjunto de significações históricas que nos afetam. Essa posição é um argumento contra o essencialismo, o qual definiria uma essência feminina e reduziria todas as mulheres a uma categoria fixa. Isso fica evidente na seguinte passagem da obra:

Todo ser humano do sexo feminino não é, portanto, necessariamente mulher; cumpre-lhe participar dessa realidade misteriosa e ameaçada que é a feminilidade. Será esta secretada pelos ovários? Ou estará congelada no fundo de um céu platônico? E bastará uma saia frufru para fazê-la descer à Terra? Embora certas mulheres se esforcem por encarná-lo, o modelo nunca foi registrado. Descreveram-no de bom grado em termos vagos e mirabolantes que parecem tirados de empréstimo do vocabulário das videntes. No tempo de santo Tomás, ela se apresentava como uma essência tão precisamente definida quanto a virtude dormitiva da papoula. Mas o conceitualismo perdeu terreno: as ciências biológicas e sociais não acreditam mais na existência de entidades imutavelmente fixadas, que definiriam determinados caracteres como os da mulher, do judeu ou do negro; consideram o caráter como uma reação secundária a uma situação. Se hoje não há mais feminilidade, é porque nunca houve. Significará isso que a palavra "mulher" não tenha nenhum conteúdo? Ê o que afirmam vigorosamente os partidários da filosofia das luzes, do racionalismo, do nominalismo: as mulheres, entre os seres humanos, seriam apenas os designados arbitrariamente pela palavra "mulher" (BEAUVOIR, 2016a, p. 9-10).

Mulheres são dotadas de particularidades que uma análise essencialista jamais consegue explorar de forma adequada. Nesse caso, a filosofia heidegge- 
riana certamente influenciou o pensamento de Simone de Beauvoir. Tanto a filósofa como o pensador existencialista Jean-Paul Sartre foram leitores atentos da principal obra do filósofo alemão, embora cada um dos franceses tenha retirado daí elementos relevantes de acordo com suas próprias convicções. Ela segue sua ruptura com a filosofia cartesiana, postura que fica evidente quando encontramos em suas obras a importância dada ao corpo, às descrições fenomenológicas e à intersubjetividade. Diante disso, também emergiu a atenção dada ao conceito de facticidade 4 . A ideia de vida fática aparece em cursos ministrados por Heidegger no período que antecedeu Ser e tempo (1927). Entretanto, quanto à influência da hermenêutica no desenvolvimento das teorias feministas na obra de Simone de Beauvoir, destacamos aqui o exemplo da hermenêutica da facticidade presente nos textos iniciais de Heidegger.

Considerado um dos maiores filósofos do século XX, Martin Heidegger se posicionou contra muitos conceitos da tradição filosófica (por exemplo, o cogito cartesiano e a definição de homem como animal racional) ao investigar a existência humana através da sua inserção no mundo e pela superação de qualquer fundamentação na consciência. O Dasein foi escolhido como termo fundamental para expressar a ideia de um ente lançado no mundo, diante de possibilidades e dotado de uma abertura privilegiada à manifestação do ser ${ }^{5}$. No entanto, nossa autora teria, por muitas vezes, permanecido fiel ao termo "sujeito". Isso quer dizer que ela preservou uma visão mais antropológica do ser humano, posição que fora evitada por Heidegger (GOTHLIN, 2003, p. 48). Por outro lado, Beauvoir mantém a importância da abertura como um suporte fundamental à facticidade humana.

Nosso encontro com o mundo não se dá como uma descoberta casual; nós estamos no mundo e com os outros porque somos abertura. Por essa razão, a existência humana é marcada pelos acontecimentos do mundo circundante e é moldada por regras de convivência. Sua apropriação do conceito de facticidade se revela evidente contra a ideia de uma natureza feminina, especialmente na medida em que a facticidade implica sempre em possibilidades. Mas seria necessário que os fundamentos das situações vividas fossem modificados, pois colocavam o sexo feminino em uma posição inferior. Eva Gothlin ressalta que:

\footnotetext{
4 Em seu curso Ontologia: hermenêutica da faticidade, de 1923, Heidegger explora e desenvolve os conceitos do título em uma linguagem bastante acessível, afirmando de forma concisa que: “Facticidade é a designação para o caráter ontológico de 'nosso' ser-ai 'próprio'. Mais especificamente, a expressão significa: esse ser-aí em cada ocasião [...] por fático chama-se algo que 'é' articulando-se por si mesmo sobre um caráter ontológico, o que é desse modo. Caso se tome a 'vida' como um modo de 'ser', então, 'vida fática' quer dizer: nosso próprio ser-aí enquanto 'aí' em qualquer expressão aberta no tocante a seu ser em seu caráter ontológico" (HEIDEGGER, 2011, p. 13-14).
}

5 Ver especialmente os $\S 1$ a $\S 5$ de Ser e tempo. 
As situações das mulheres geralmente têm sido caracterizadas por possibilidades menores, conclui Beauvoir. Isso resulta do fato de ela ter sido definida como "o Outro". Portanto, a situação delas não é a mesma, mesmo quando um homem e uma mulher têm o mesmo emprego e o mesmo salário (GOTHLIN, 2003, p. 53-54).

E na mesma trilha de que cada existência é marcada por uma situação vivida, a conexão com o mundo também se dá pelo corpo, isto é, não se limita a um contato pela consciência, a qual supostamente seria o fundamento de todo e qualquer sentido. O próprio corpo é uma situação e sobre isso, Gothlin destaca que

um ser humano não é uma consciência relacionada como sujeito ao corpo como um objeto. Em vez disso, a pessoa vive o corpo como uma situação. [...] Se o corpo é uma situação, também faz parte de uma situação sociocultural maior (GOTHLIN, 2003, p. 54).

As diferenças entre homens e mulheres são de fato relevantes. Todavia, não significa que mulheres estejam condicionadas a determinado modo de vida por conta de qualquer especificidade. A situação também é determinante de seus atos. Conforme Beauvoir:

[...] o corpo da mulher é um dos elementos essenciais da situação que ela ocupa neste mundo. Mas não é ele tampouco que basta para a definir. Ele só tem realidade vivida enquanto assumido pela consciência através das ações e no seio de uma sociedade; a biologia não basta para fornecer uma resposta à pergunta que nos preocupa: por que a mulher é o Outro? Trata-se de saber como a natureza foi nela revista através da história; trata-se de saber o que a humanidade fez da fêmea humana (BEAUVOIR, 2016a, p. 65).

Como um corpo que passa pela puberdade, pelas dores do período menstrual e suas alterações de humor, pelo parto e o esgotamento da maternidade até chegar aos incômodos da menopausa pode ser considerado fraco? Como uma existência que convive com assédio nas ruas e no ambiente do trabalho, por exemplo, é considerada fraca se precisa resistir todos os dias? Se o corpo é naturalmente forte 
porque suporta todas essas experiências, a fraqueza feminina é uma construção social e histórica. Foram os homens que excluíram as mulheres e inventaram a divisão entre os sexos, criando privilégios para eles próprios. A filósofa brasileira Djamila Ribeiro comenta a questão de forma bastante elucidativa:

A aplicação da biologia na questão de gênero nos faz tomar uma diferença biológica como social. E a mulher não pode ser definida unicamente pela biologia ou sua sexualidade porque a consciência que a mulher adquire de si mesma é apreendida na sociedade a qual ela é membro. O homem é tido ainda como o soberano não porque tem uma anatomia diferente da mulher, mas porque principalmente quem possui essa anatomia diferente possui um prestígio social. Logo, percebe-se que não se pode ignorar o fato histórico e social. [...] Nesse viés biológico, por exemplo, o termo fêmea prende a mulher ao seu sexo e a consequência disso é nunca se libertar de uma situação (RIBEIRO, 2013, p. 507).

E prender a mulher ao seu próprio sexo é defini-la como o segundo sexo, ou seja, ela se torna dotada de categorias restritivas que a impedem de experimentar suas possibilidades, ao passo que o homem permanece o sujeito principal de todo o saber e de experiências concretas. Segundo Beauvoir, qualquer ser humano é capaz de transcender para o mundo, se desenvolver e superar a espécie; em resumo, a vida humana é baseada na noção de projeto. Mas apenas o homem foi incentivado a superar a si mesmo, realizar novas descobertas, trabalhar, narrar os fatos, estabelecer objetivos e exercer seu poder. Enquanto caberia a ele a construção do mundo, a mulher foi excluída da criação de leis, valores e teorias. A mulher não se manifestava igualmente na vida pública nem tinha muitas chances de compartilhar suas ideias, visto que ela permaneceu reduzida à condição de reprodutora ou então era considerada sentimental e fraca.

A construção de um imaginário em torno do sexo feminino deixou subentendido que lhe faltavam habilidades, conhecimento, rigor técnico e força para transcender. Simone de Beauvoir afirma que:

[...] a mulher nunca teve chance em nenhum terreno. Eis por que reclamam hoje elas hoje, em grande número, novo estatuto; e, mais uma vez, sua reivindicação não consiste em serem exaltadas em sua feminilidade: elas querem que em 
si próprias, como no resto da humanidade, a transcendência supere a imanência; elas querem que lhes sejam concedidos, enfim, os direitos abstratos e as possibilidades concretas, sem a conjugação dos quais a liberdade não passa de mistificação (BEAUVOIR, 2016a, p. 191).

A emancipação pessoal da mulher depende da sua capacidade de transcender e ir além do espaço doméstico. No entanto, através de uma construção cultural, ela foi transformada no outro do homem - uma espécie de posse, objeto inferior e dependente dele, apenas um segundo sexo. Nesse cenário, nenhuma mulher é capaz de alcançar liberdade individual na proporção em que suas condições de vida impedem que todas as mulheres sejam igualmente livres. Afinal, afirma Beauvoir, "não foi a inferioridade feminina que determinou sua insignificância histórica: sua insignificância histórica foi que as votou à inferioridade" (BEAUVOIR, 2016a, p. 190). Todo o esforço da pensadora francesa no tratado permite que possamos descrever experiências a partir do modo de ser no mundo. Além disso, fazer uma análise histórica é fundamental, pois revela como a construção de uma sociedade patriarcal se apoia equivocamente sobre fatores biológicos, culturais e históricos.

De certo, a facticidade se opõe à ideia de uma natureza feminina e, portanto, é um argumento contra o sexismo biológico e nos faz perceber o conceito de situação como um elemento orientador para as teorias feministas. As próprias situações vividas pela autora conduziram seu envolvimento com a questão das mulheres, a qual estava diretamente interligada com temas da fenomenologia, do existencialismo e da epistemologia. A instabilidade dos períodos de guerras e o pós-guerra contribuíram para que certezas previamente estabelecidas fossem severamente questionadas; o existencialismo trouxe à superfície as perguntas desafiadoras sobre o que nos define, contrariando a ideia de essência; a fenomenologia da percepção deu relevância aos temas do corpo e introduziu a perspectiva de que somos mais do que consciência; o debate sobre os direitos das mulheres voltou a ser bastante difundido e aprofundado a partir do desejo de liberdade.

Investigar as mulheres pela via da corporeidade é fundamental, uma vez que somos mais do que entes pensantes: somos concretas, encarnadas, temos um corpo e ocupamos um lugar no mundo; temos direito a movimento, a tomarmos decisões e a seguirmos caminhos diferentes daqueles impostos pelas divisões de gênero. $O$ essencialismo, doutrina que defende uma essência pressuposta aos entes, é insuficiente por não pensar as diferenças atinentes às mulheres e as teorias supostamente feministas daí surgidas se voltam apenas para aquelas 
que se encaixariam na essência feminina - que geralmente abrange mulheres brancas e heterossexuais, por exemplo. É preciso destacar que Beauvoir não discutiu todas as especificidades que cabem no termo mulher. No entanto, foi justamente sua compreensão de que as opressões estão fundamentadas no sexismo biológico, em construções sociais e fatores psicanalíticos o que tornou sua filosofia tão inovadora para as correntes feministas.

A mulher não é qualificada unicamente por uma essência feminina porque só pode ser definida por suas ações e escolhas; enfim, ela é sua própria existência. A crítica ao essencialismo aparece na primeira autobiografia de Simone de Beauvoir, intitulada Memórias de uma moça bem-comportada. No texto de 1958, ela relembra sua infância, juventude e os anos iniciais de estudos filosóficos, assim como as principais motivações que a conduziram na escolha de sua vida profissional. De forma decisiva, ela expõe que "era preciso destinar a vida a saber por que se vivia: entrementes, nada se devia encarar como dado e sim basear seus valores em atos de amor e de vontade indefinidamente renovados" (BEAUVOIR, 2015, p. 229).

Logo, a vida não é algo predeterminado, pois a construímos a partir de decisões que precisamos tomar diante de ocorrências impostas. Tal concepção seria atípica para uma jovem burguesa. Entretanto, ela enxergou nos valores estabelecidos uma construção social que limitava mulheres a determinada forma de vida. E era de tal destino que a futura filósofa já ansiava por escapar. Foi nesse contexto que a situação das mulheres apareceu como pressuposto para explicar todas as opressões sofridas por elas, mas também se destacou na filosofia beauvoiriana como possibilidade para a conquista de uma existência autêntica. $\mathrm{Ou}$ seja, ao mesmo tempo em que a mulher se inscreve em um quadro no qual é impossível ter completo domínio da subjetividade, ela pode se tornar um sujeito livre e responsável. Para isso, antes seria necessário revolver as regras criadas pelos homens para que se pudessem modificar experiências denominadas femininas e, enfim, reverter o papel das instituições sociais que naturalizam a situação vivida (HENRIQUES, 2016, p. 156).

Como diz a pensadora francesa: "Um existente não é senão o que faz; o possível não supera o real, a essência não precede a existência: em sua pura subjetividade o ser humano não é nada. Medem-no pelos seus atos" (BEAUVOIR, 2016a, p. 333). Ao seguir a máxima existencialista que coloca a existência enquanto predecessora da essência (SARTRE, 2014, p. 18), sua filosofia nos abre para uma postura de liberdade e levanta uma questão pertinente: o que é ser mulher? Assim, pensar sobre a construção de um sexo feminino é colocar em discussão incontáveis imposições para que as limitações decorrentes sejam negadas como dados imutáveis sobre o que podemos ou não realizar no mundo. 


\section{Considerações finais}

O que pode a filosofia oferecer para que as mulheres sejam colocadas no lugar de sujeito do conhecimento e não serem reduzidas a um papel de "outro"? A partir de quais correntes filosóficas elas são compreendidas em suas vivências? $\mathrm{E}$ as teses iluministas seriam capazes de dar conta de uma filosofia feminista? A hermenêutica, a epistemologia e o existencialismo, por exemplo, trazem ricas contribuições para teorias feministas. Acreditamos que análises filosóficas e históricas devem necessariamente incluir mulheres e suas obras, assim como jamais devem eliminar as questões relativas às suas experiências. É interessante partirmos de uma hermenêutica para renovar toda leitura do mundo e, ao articularmos o pensar filosófico com o feminismo, podemos analisar os problemas concretos de forma adequada.

Diante do ideal iluminista que assegura a razão como propriedade de conhecimento comum a todos os seres humanos, é fundamental estabelecermos epistemologias que nos permitam criar narrativas sobre as vivências humanas. Ao defender que somos racionais e pensantes, devemos partir dessa igualdade em direção às diferenças específicas das mulheres. Então, seremos capazes de pensar as opressões sofridas por mulheres negras, lésbicas, transexuais e/ou periféricas, pois suas opressões merecem debates apropriados e particulares. Hoje, por exemplo, discutimos tais questões a partir da concordância de que mulheres possuem diferentes experiências vividas, na proporção em que cada uma é permeada por condições próprias e existem privilégios a serem superados para que possamos encontrar igualdade.

As ideias de Mary Wollstonecraft são válidas, pois colocam a necessidade de uma educação igualitária que conserva nossas virtudes. E o seu próprio exemplo sugere o quanto foi importante questionar os ideais de seu tempo, com o objetivo de refutar na história da filosofia as teses que sustentavam os costumes e, a partir delas, modificar tais costumes e suas implicações na construção da vida social. A filósofa reconheceu que a razão é igual em homens e mulheres. Portanto, a educação e os modelos de comportamento deveriam ter como pressuposto essa igualdade. Muito além da racionalidade, reconhecer que somos entes corpóreos, que vivemos em ambientes marcados por eventos específicos e que estamos cercadas por circunstâncias, é afirmar que mulheres possuem manifestações próprias que os homens jamais serão capazes de assimilar e que, entre as experiências consideradas femininas, existem muitas das quais nem mesmos todas as mulheres poderão tomar parte.

O processo histórico é um fator determinante para moldar a existência humana e, por isso, é preciso intervir no contexto e na cultura aos quais estamos ligados sempre que estes limitam nossas liberdades. Assim, Fernanda Henriques comenta que: 
Conhecemos a realidade e intervimos nela através de condicionamentos inerentes a sermos humanos: a nossa inserção histórica, social, e cultural e o facto de termos um corpo fazem do discurso humano, qualquer que ele seja, uma interpretação mais ou menos validada pelas premissas e axiomas em que se inscreve. Esta perspectiva opõe-se ao padrão epistemológico ocidental que instaurou as ideias de neutralidade, universalidade e objectividade como apanágios da verdade e do valor do saber, assentes na ideia de uma razão pura, transparente e asséptica que produzisse e fornecesse um conhecimento sem mácula ou impressão digital [...] (HENRIQUES, 2010, p. 13-14).

Uma tarefa da hermenêutica é realizar interpretações constantes da existência e do mundo circundante. No que se refere à importância de construirmos uma nova estrutura social, a hermenêutica desvela e compreende a realidade para que possamos modificá-la justamente quando não está mais de acordo com nossas concepções e necessidades. Ou seja, uma interpretação adequada do nosso lugar no mundo ajuda a desconstruirmos um modelo misógino que oculta nossas batalhas e conquistas, que nos limita enquanto seres humanos, que nos transforma em entes derivados de todo ideal masculino ${ }^{6}$. Por seu turno, quando se trata do campo da epistemologia e da razão, o homem se transformou no sujeito de conhecimento, embora por muito tempo tal modelo tenha priorizado o sujeito masculino branco, europeu e de classe alta (HENRIQUES, 2010, p. 19).

Ainda assim, a exclusão das mulheres se deu como um processo natural para os homens, pois eles sempre as consideraram biologicamente incapazes. Ketzer destaca que "o modelo masculinista a partir do qual a ciência foi desenvolvida tem um papel político central, na medida em que reforça as relações de dominação a que as mulheres são submetidas" (KETZER, 2017, p. 101). Na ciência, por exemplo, ainda são adotadas categorias iluministas que mantêm a hegemonia masculina e essa postura se transpõe para a vida cotidiana. Podemos então fazer uma nova leitura da história da filosofia, utilizar o pensamento filosófico para levantar perguntas fundamentais sobre nossas vivências e questionar a estrutura do mundo que nos circunda.

6 Esse trabalho é essencial justamente porque mexe com o entendimento de como somos moldadas a partir das concepções que nivelam nossas ações e escolhas. Sobre isso, Fernanda Henriques comenta que: "No caso das representações do feminino, o trabalho de interpretação do legado cultural é particularmente delicado porque tem de ser feito ao arrepio daquilo que mais profundamente nos constitui, tendo de começar por uma desconstrução e por uma hermenêutica da suspeita, uma vez que as representações do feminino mais enraizadas advém de uma concepção antropológica assimétrica, que toma o masculino como padrão e o feminino como derivado" (HENRIQUES, 2010, p. 15). 
Logo, construir novas epistemologias permite (1) colocarmos a mulher no centro de reflexões e discutirmos seus problemas levando em consideração suas particularidades, onde tais experiências não a excluem da principal definição de que mulheres são seres humanos; e (2) enxergarmos a mulher como sujeito do conhecimento, isto é, aquela que pensa, experimenta, percebe, produz saber, filosofa, constrói a história e transforma o mundo. O existencialismo também é um caminho para a construção de uma nova estrutura social. Para Sartre, o existencialismo é "uma doutrina que torna a vida humana possível e que, por outro lado, declara que toda verdade e toda ação implicam um meio e uma subjetividade humana" (SARTRE, 2014, p.16). Trata-se de uma filosofia que analisa a existência a partir de suas escolhas e da situação no mundo.

Adotar uma postura existencialista é lutar contra uma limitadora essência feminina e entender que devemos sempre buscar nossa liberdade apesar de tudo o que é dado como pressuposto. Ser existencialista é perceber as experiências vividas e assumir todas as consequências resultantes das nossas decisões. Mas acima de tudo, significa buscar transcender a própria subjetividade, especialmente quando se trata de uma categoria imposta através de opressões e ideologias criadas de forma exclusiva pelo sexo masculino. Assim, livre da supremacia masculina, a filosofia é um modo de saber enriquecedor para trazermos uma nova perspectiva sobre a condição e as experiências das mulheres. E foi esse caminho que Mary Wollstonecraft e Simone de Beauvoir trilharam, deixando como legado novos caminhos e possibilidades.

Recebido em: 09.11.2019| Aprovado em: 28.02.2020

BEAUVOIR, Simone de. Memórias de uma moça bem-comportada. Tradução de Sérgio Milliet. Rio de Janeiro: Nova Fronteira, 2015.

.O segundo sexo: fatos e mitos, vol. 1. $3^{\text {a }}$ ed. Tradução de Sérgio Milliet. Rio de Janeiro: Nova Fronteira, 2016a.

.O segundo sexo: a experiência vivida, vol.

2. $3^{\mathrm{a}}$ ed. Tradução de Sérgio Milliet. Rio de Janeiro: Nova Fronteira, 2016b.
GOTHLIN, Eva. Reading Simone de Beauvoir with Martin Heidegger. In: CARD, Claudia (Ed.) The Cambridge Companion to Simone de Beauvoir. Cambridge: Cambridge University Press, 2003.

HEIDEGGER, Martin. Ontologia: hermenêutica da faticidade. Tradução de Márcia Sá Cavalcante Schuback. Petrópolis: Vozes, 2011.

Ser e tempo. Tradução de Fausto Castilho. Campinas: Editora Unicamp; Petrópolis: Vozes, 2012. 
HENRIQUES, Fernanda. Concepções filosóficas e representações do feminino: Subsídios para uma hermenêutica crítica da tradição filosófica. In: Revista Crítica de Ciências Sociais, n ${ }^{\circ}$, Coimbra, 2010, pp. 11-28.

. Filosofia e gênero: outras narrativas sobre a tradição ocidental. Lisboa: Edições Colibri, 2016.

KETZER, Patricia. Como pensar uma Epistemologia Feminista? Surgimento, repercussões e problematizações. In: Argumentos: Revista de filosofia, vol. 9, Fortaleza, 2017, pp. 95-106.

LINDEMANN, Kate. Mary Wollstonecraft. In: WAITHE, Mary Ellen (Ed.), A history of women philosophers, vol. 3, 1600-1900. Kluwer Academic Publishers: Dordrecht /Boston /London, 1991.

MIRANDA, Anadir. Mary Wollstonecraft e a reflexão sobre os limites do pensamento iluminista a respeito dos direitos das mulheres. In: Revista Vernáculo, vol. 2, Curitiba, 2010, pp. 110-164.

RIBEIRO, Djamila. Para além da biologia: Beauvoir e a refutação do sexismo biológico. In: Sapere Aude., vol. 4, no 7, Belo Horizonte, 2013, pp. 506-509.

SARTRE, Jean-Paul. O existencialismo é um humanismo. Tradução de João Batista Kreuch. $4^{\text {a }}$ edição. Petrópolis: Vozes, 2014.

WOLLSTONECRAFT, Mary. Reivindicação dos direitos da mulher. Tradução de Ivania Pocinho Motta. São Paulo: Boitempo, 2016. 